Esta revista forma parte del acervo de la Biblioteca Jurídica Virtual del Instituto de Investigaciones Jurídicas de la UNAM

\title{
DEMOCRACIA Y CIUDADANÍA. EL CAMINO DE LA TRANSPARENCIA
}

\section{Frida Carolina BARRIOS MEDINA*}

Para considerar a un país democrático es preciso garantizar que los ciudadanos ejerzan un contrapeso real frente a sus representantes, los políticos en el poder. Sin embargo, en América Latina las democracias incipientes requieren todavía avanzar en sus procesos institucionales de control hacia sus gobernantes. En ese sentido, la transparencia en México se ha inscrito como un mecanismo para avanzar en la democratización, donde las organizaciones no gubernamentales han trabajado por exigir esta prerrogativa ciudadana. Se trata de un tema actual ante la creación del sistema nacional anticorrupción que promueve sanciones y mecanismos de control para los funcionarios y políticos, pero antes de ello es preciso construir las vías para el acceso a la información.

En el libro se describe el papel que han tenido las organizaciones no gubernamentales, desde una mirada del Colectivo por Municipios Transparentes (Cimtra), que desde 2002 han trabajado en México para exigir el cumplimiento al derecho de acceso a la información consagrado en el artículo 6o. constitucional. Además, se describen las experiencias de la organización desde el ámbito local, porque desde su nacimiento se ha enfocado a este nivel de gobierno. El hilo conductor de este trabajo colectivo es destacar la transparencia como el principal mecanismo para vigilar, controlar y acotar el poder de los funcionarios públicos y representantes, aportando experiencias que son posibles replicar en otros espacios.

* Estudiante de la Licenciatura en Políticas Públicas en la Universidad Autónoma Metropolitana. Miembro del Colectivo por Municipios Transparentes en el Estado de México. Actualmente es asistente de investigación en el Centro Estratégico de Estudios Municipales; freebird9714@gmail.com. 
Esta revista forma parte del acervo de la Biblioteca Jurídica Virtual del Instituto de Investigaciones Jurídicas de la UNAM

La obra está divida en dos grandes temas; por una parte, describe los esfuerzos institucionales promovidos por el Estado mexicano para avanzar en materia de transparencia, por medio de las leyes expedidas para tal efecto, desde la promulgación de la Ley de Transparencia y Acceso a la Información Publica, aprobada en junio de 2002 y reformada en 2014, hasta las modificaciones para alinearse con el sistema nacional anticorrupción. Por otra parte, describe las experiencias de las organizaciones para fomentar y promover el seguimiento de los recursos públicos para contrarrestar la opacidad de los gobiernos locales.

Se inscribe a la transparencia como uno de los mecanismos más efi- cientes para la construcción de la ciudadanía; es decir, la transparencia - para promover la participación activa de los ciudadanos en la lucha de sus demandas y peticiones hacia la contraloría social y el ejercicio de sus derechos como contralores sociales, para conocer en todo momento las intenciones, conducta y desempeño de los gobernantes. Parte de la premisa es la de "democratizar este país a partir de recuperar el interés ciudadano, mediante la institucionalización del proceso de rendición de cuentas".

En la compilación de experiencias se construye un discurso de gobernanza a partir de la evaluación de los municipios pertenecientes a los siguientes estados: Tlaxcala, Puebla, Zacatecas, Veracruz, Morelos, Nuevo León, Baja California, Chihuahua, Tabasco, Colima, Guerrero, Jalisco, Guanajuato y el Estado de México. Además, explica los obstáculos presentados para conocer los sueldos, salarios, planes de desarrollo y obras públicas. La opacidad se valora negativamente en los informes que distribuye el colectivo Cimtra y la difusión de resultados permite a los sujetos obligados mejorar su respuesta. Este es un logro que describe el papel de las organizaciones que han buscado incidir de manera positiva en la transparencia municipal.

A través de los 12 capítulos que presenta la obra, se discuten las formas de participar en la construcción de sistemas de transparencia y uso de tecnología para difundir información útil para los usuarios, porque mucha información alojada en los portales de los ayuntamientos es confusa, desactualizada o forma parte de las prácticas de transparencia simulada que permean la mayoría de casos. Cecilia Cadena Inostroza (en el libro que coordina, Transparencia y opacidad) ${ }^{1}$ afirma que los gobiernos locales carecen de capacidades institucionales para garantizar la transparencia y la rendición de cuentas. Es preciso adoptar mecanismos de contraloría social e innovación de las organizaciones como ejercicio democrático para evitar el abuso de los gobernantes.

1 El titulo completo es Transparencia y opacidad. Mediciones y prácticas organizacionales en municipios. Ilustrado con casos del Estado de México, El Colegio Mexiquense, 2015. 
Esta revista forma parte del acervo de la Biblioteca Jurídica Virtual del Instituto de Investigaciones Jurídicas de la UNAM

Asimismo, el trabajo compila evidencias empíricas y estudios de casos, aporta evidencias para comprender el fenómeno de opacidad que priva en la mayoría de las estructuras de gobierno subnacional. Este fenómeno es producto de la cultura y la ausencia de mecanismos institucionales para fomentar la difusión de información, así como de las tensiones políticas entre partidos políticos y la falta de aplicación de la ley.

Si bien es cierto que se ha avanzado en la construcción de leyes y reglamentos, también se impone la ausencia de capacidades institucionales para hacer posible la transparencia en el gobierno local. La modificación en el artículo sexto constitucional privilegia la digitalización de los archivos, documentos e información pública; incluso la nueva Ley de Transparencia y Acceso a la Información Pública, en su artículo 40, señala más de 50 obligaciones de información y datos (que por supuesto pocos ayuntamientos podrán cumplir en la fecha límite marcada para el 2017). Por tanto, la transparencia se convierte en un anhelo difícil de cumplir si consideramos las limitaciones existentes.

\section{Incidencia de las organizaciones}

El libro explora la realidad en torno a la transparencia en México y ofrece un fino diagnóstico de lo que sucede en nuestro país mediante un ejercicio retrospectivo de análisis histórico. Cimtra, desde 2002, impulsó una agenda de trabajo conjunto con algunos gobiernos interesados en promover una relación conjunta entre autoridades y ciudadanos. El trabajo de recopilación de información sobre los casos es enorme, detallado y enriquecedor para los estudiosos de la administración pública municipal.

La difusión de los casos es una herramienta eficaz para el control de los políticos. Claudio Ferraz y Federico Finan (en su texto Exposing corrupt politicians: the effects of brazil's publicly released audits on electoral outcomes $)^{2}$ demuestran cómo a mayor información los ciudadanos pueden ejercer mecanismos de control sobre sus representantes. Además, la difusión de casos de corrupción y mal uso de recursos genera desprestigio y efectos electorales adversos. Así, el colectivo Cimtra documenta los casos de cada municipio evaluado y publica un ranking como mecanismo de incidencia, documentado en esta obra.

Los autores de esta compilación coinciden en señalar que no sólo se precisa de leyes y reglamentos para garantizar la transparencia en los espacios locales, también es necesario contar con disposición y voluntad polí-

2 Publicado en The Quarterly Journal of Economics en mayo de 2008. 
Esta revista forma parte del acervo de la Biblioteca Jurídica Virtual del Instituto de Investigaciones Jurídicas de la UNAM

tica. Por ejemplo, en el caso del Estado de México existen municipios con más de 70 mil habitantes que no cuentan con página web activa. Lo mismo sucede en el estado de Puebla, que tiene más de 217 municipios, todos ellos heterogéneos, pero que los pocos que cuentan con infraestructura carecen de vocación por hacer públicos sus archivos, información y datos de interés público.

Construir confianza y certidumbre a los gobernados es lo que otorga la transparencia a los gobernantes. Por ello, en las líneas de debate y análisis de los gobiernos locales, ofrece un diagnóstico certero sobre las posibilidades que entraña abrir la información a los solicitantes, porque no sólo se - trata de sueldos y salarios de los políticos; el ejercicio de ofrecer informa-

- ción puede ayudar a reconocer los derechos, las oportunidades y las posibilidades. Este manuscrito contiene una serie de casos documentados donde las organizaciones están buscando datos sobre salud, medio ambiente, recursos públicos, opciones educativas y muchos más ejemplos del uso de los datos. Avanzar hacia el gobierno abierto es el siguiente peldaño en los escalones de fortalecimiento cívico y social que impulsan los casos de solicitudes hechas a los gobiernos, las cuales nutren las páginas del libro.

Pese a contar con leyes apropiadas, mecanismos de solicitud y un órgano encargado de garantizar la transparencia, los autores señalan que es preciso avanzar en la institucionalización de las sanciones, de los mecanismos de control y el desarrollo democrático. José Ojeda Bustamante y José Antonio Meyer, coordinadores de la publicación, son investigadores, y desde la academia postulan varias propuestas de incidencia, como el promover la acción colectiva y despertar de la sociedad civil, pero también la construcción de órganos garantes autónomos y libres; explican que mientras los organismos de transparencia sean cuotas partidistas, poco se podrá avanzar en la democratización.

\section{La transparencia posible}

El trabajo reúne a especialistas en transparencia y describe en sus capítulos la asimetría en la información que tienen los gobiernos municipales. En el ranking de municipios evaluados, pocos son los que logran calificaciones favorables. Esto sucede por dos motivos: la falta de interés de los gobernantes y la ausencia de capacidades técnicas, pero también ocurre por la ausencia de castigo y mecanismos coercitivos. Muchos municipios no cuentan con una computadora y menos con un escáner que les permita digitalizar los documentos, sostiene la investigación. 
Esta revista forma parte del acervo de la Biblioteca Jurídica Virtual del Instituto de Investigaciones Jurídicas de la UNAM

Empero, se señalan casos de éxito en el libro, pues hay municipios que se han mostrado dispuestos a participar y mediante un acompañamiento es posible mejorar sus prácticas, como el ayuntamiento de Guadalajara, Jalisco, con una creciente modificación en el uso de archivos a disposición de los usuarios y solicitantes. En el capítulo XI se detalla el papel de los partidos políticos como sujetos obligados a transparentar el ejercicio de los recursos de los contribuyentes, los cuales, al igual que los sindicatos, todavía tienen muchas áreas de oportunidad.

En las prácticas negativas, sobre las que alerta este trabajo de investigación multidisciplinario, se encuentra la reserva de datos, usada para ocultar información sobre obras y finanzas municipales. Un cambio institucional, como se plantea en el libro, con estudios de casos y la revisión precisa de éstos, sólo puede ser posible con un cambio organizacional, romper con las inercias que subsisten dentro de las administraciones públicas locales. Ante la ausencia de reelección, muchos alcaldes adoptan una visión oportunista y desvían fondos, actúan sin mecanismos de control y por ello el papel de los institutos de transparencia resulta fundamental, como exponen las reflexiones finales que contiene el libro.

Finalmente, este libro llama a la población a que ejerza su ciudadanía mediante la inserción directa o indirecta en las decisiones políticas de su país; es el inicio de un trabajo que tiene aún mucho por abordar y mucho que cimentar, porque, como lo mencionan los autores en el libro, la transparencia y rendición de cuentas no desaparecerán la corrupción, sino que es el inicio de todo un proceso lento que necesita el apoyo de toda la población y de las mismas instituciones para poder construir instituciones transparentes en vías de la democracia.

\section{Bibliografía del Libro RESEÑAdo}

Ojeda Bustamante, José y Meyer Rodríguez, José Antonio (coords.), 2016, Democracia y ciudadanía. El camino de la transparencia, México, Universidad Autónoma del Estado de México-Colectivo por Municipios Transparentes-Consejo Latinoamericano de Ciencias Sociales-Benemérita Universidad Autónoma de Puebla, disponible en: http://ri.uaemex. $m x / h a n d l e / 20.500 .11799 / 62691$. 